\title{
The uptake of $\mathrm{SO}_{2}$ on Saharan dust: a flow tube study
}

\author{
J. W. Adams ${ }^{1}$, D. Rodriguez ${ }^{2}$, and R. A. Cox ${ }^{1}$ \\ ${ }^{1}$ Centre for Atmospheric Science, Chemistry Department, University of Cambridge, UK \\ ${ }^{2}$ Facultad de Ciencias del Medio Ambiente, Departamento de Quimica Fisica, Universidad de Castilla-La Mancha, Avda. \\ Carlos III s/n, Campus Tecnologico, 45071-Toledo, Spain
}

Received: 24 February 2005 - Published in Atmos. Chem. Phys. Discuss.: 3 May 2005

Revised: 12 August 2005 - Accepted: 6 September 2005 - Published: 12 October 2005

\begin{abstract}
The uptake of $\mathrm{SO}_{2}$ onto Saharan mineral dust from the Cape Verde Islands was investigated using a coated wall flow tube coupled to a mass spectrometer. The rate of loss of $\mathrm{SO}_{2}$ to the dust coating was measured and uptake coefficients were determined using the measured BET surface area of the sample. The uptake of $\mathrm{SO}_{2}$, with an initial concentration between $(2-40) \times 10^{10}$ molecule $\mathrm{cm}^{-3}(0.62-$ $12 \mu$ Torr), was found to be strongly time dependent over the first few hundred seconds of an experiment, with an initial uptake $\gamma_{0, \text { BET }}$ of $(6.6 \pm 0.8) \times 10^{-5}(298 \mathrm{~K})$, declining at longer times. The amount of $\mathrm{SO}_{2}$ adsorbed on the dust samples was measured over a range of $\mathrm{SO}_{2}$ concentrations and mineral dust loadings. The uptake of $\mathrm{SO}_{2}$ was found to be up to $98 \%$ irreversible over the timescale of these investigations. Experiments were also performed at $258 \mathrm{~K}$, at a relative humidity of $27 \%$ and at $298 \mathrm{~K}$ in the presence of ozone. The initial uptake and the amount of $\mathrm{SO}_{2}$ taken up per unit area of BET dust surface was the same within error, irrespective of the conditions used; however the presence of ozone reduced the amount of $\mathrm{SO}_{2}$ released back into the gas-phase per unit area once exposure of the surface ended. Multiple uptakes to the same surface revealed a loss of surface reactivity, which did not return if the samples were exposed to gas-phase water, or left under vacuum overnight. A mechanism which accounts for the observed uptake behaviour is proposed and numerically modelled, allowing quantitative estimates of the rate and amount of $\mathrm{SO}_{2}$ removal in the atmosphere to be estimated. Removal of $\mathrm{SO}_{2}$ by mineral dust is predicted to be significant at high dust loadings.
\end{abstract}

\footnotetext{
Correspondence to: R. A. Cox

(rac26@cam.ac.uk)
}

\section{Introduction}

Mineral dust represents between one-third and one-half of the estimated total annual primary aerosol emissions into the atmosphere by mass, with current estimates of between 1000 and $3000 \mathrm{Tg}$ per year (Penner et al., 2001). The majority of sources are situated in the arid regions of the Northern Hemisphere, which lie in a broad band that extends from the west coast of North Africa, over the Middle East, Central and South Asia, to China (Prospero et al., 2002). Dust particles with typical volume median diameters $(2-4 \mu \mathrm{m})$ have an atmospheric lifetime of several weeks (Prospero, 1999) and can be transported thousands of kilometres across the N. Atlantic (Formenti et al., 2001) and the N. Pacific (VanCuren and Cahill, 2002). As the dust is transported its composition changes, with the finer clays retained relative to the coarser quartz. In addition the composition of the dust is modified by heterogeneous reactions of oxides and oxyacids, forming sulphate and nitrate. In the case of the Saharan source, the dust is transported in the Saharan Air Layer (SAL), at altitudes between 1 and $\sim 4.5 \mathrm{~km}$ across the Atlantic Ocean. Heterogeneous reactions on mineral dust have been summarised in a recent review (Usher et al., 2003).

The focus of this investigation is the uptake and interaction of sulphur dioxide $\left(\mathrm{SO}_{2}\right)$ with Saharan mineral dust. $\mathrm{SO}_{2}$ is the predominant gaseous sulphur-containing atmospheric trace gas. It is released to the troposphere by fossil fuel combustion, volcanic emissions as well as through oxidation of DMS and other sulphur compounds of biogenic origin. Typical tropospheric mixing ratios are of the order of $10 \mathrm{pptv}$ in remote regions, rising to several hundred ppb in polluted urban areas. The lifetime of $\mathrm{SO}_{2}$ in the free troposphere is up to $\sim 15$ days (Hanke et al., 2003). It is oxidised in the troposphere to form sulphates, which may occur in the gas-phase (principally via reaction with $\mathrm{OH}$ to yield $\mathrm{H}_{2} \mathrm{SO}_{4}$ ), in cloud or fog droplets, or on aerosol particles.

(C) 2005 Author(s). This work is licensed under a Creative Commons License. 


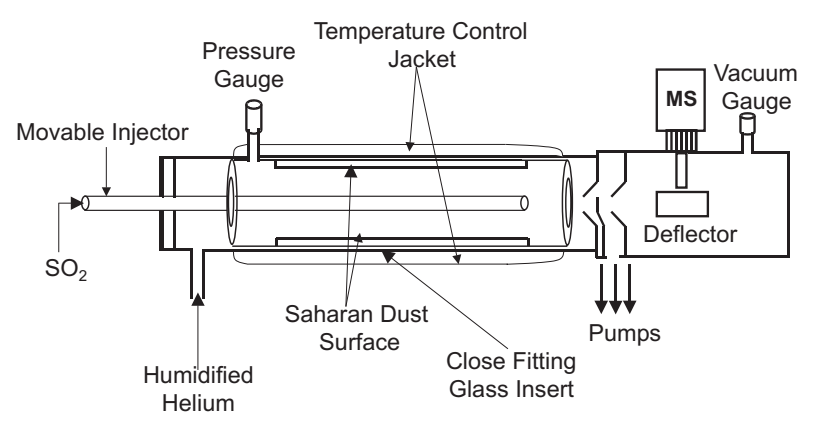

Fig. 1. Schematic diagram of the experimental set-up.

Field, laboratory and modelling studies provide convincing evidence that mineral dust can play an important role in the chemistry of sulphur dioxide (Dentener et al., 1996; Song and Carmichael, 1999). Recent field studies have recorded anti-correlations between the concentration of sulphur dioxide and Saharan (Andreae et al., 2003; Hanke et al., 2003) or Chinese (Tang et al., 2004) desert dust loading. From these observations it is apparent that mineral dust affects the local gas-phase concentration of $\mathrm{SO}_{2}$, either by physical adsorption or by heterogeneous reaction. Once on the surface the adsorbed $\mathrm{SO}_{2}$ may react. Sulphate formation has been observed in laboratory studies following the uptake of $\mathrm{SO}_{2}$ in air onto a variety of dusts and their component metal oxides (Judeikis et al., 1978; Mamane and Gottlieb, 1989) and analysis of atmospheric mineral dust particles shows they are often coated with sulphates (Dutkiewicz et al., 2000), although this coating could be partially due to deposition of sulphuric acid vapour.

To model the effect of mineral dust on the fate of atmospheric $\mathrm{SO}_{2}$ the rate of processing needs to be known. In addition the mechanism of $\mathrm{SO}_{2}$ processing on mineral dust is uncertain (Dentener et al., 1996). It is well known that $\mathrm{SO}_{2}$ can be oxidized to sulphate in aqueous aerosol by ozone and hydrogen peroxide (Chameides and Stelson, 1992; Keene et al., 1998; Krischke et al., 2000), and it has been proposed that ozone can oxidise adsorbed sulphite to sulphate on solid particle surfaces (Maahs, 1983).

Recently, the heterogeneous reactivity of $\mathrm{SO}_{2}$ has been studied on metal oxides (Goodman et al., 2001; Usher et al., 2002), China Loess (Usher et al., 2002) and Saharan mineral dust (Ullerstam et al., 2002; Ullerstam et al., 2003). The initial uptake coefficient of $\mathrm{SO}_{2}$ onto metal oxides was found to be of the order of $10^{-5}$ and the maximum surface coverage on these metal oxides was found to be of the order of $10^{14}$ molecule $\mathrm{cm}^{-2}$. Usher et al. (2002) have studied the heterogeneous uptake and oxidation of $\mathrm{SO}_{2}$ on China Loess, determining an initial uptake coefficient of $(3 \pm 1) \times 10^{-5}$. Ullerstam et al. (2002) used diffuse reflectance infrared Fourier transform spectroscopy (DRIFTS) to interrogate surface bound sulphur species in a study of $\mathrm{SO}_{2}$ uptake onto Saharan mineral dust in the presence of $\mathrm{O}_{3}$. They derived a time-averaged uptake coefficient of $(5.0 \pm 1.2) \times 10^{-7}$ and a maximum surface coverage of $4 \times 10^{13} \mathrm{~cm}^{-2}$. In a later study with $\mathrm{NO}_{2}$ also present, these authors (Ullerstam et al., 2003) used a Knudsen cell coupled to a quadrupole mass spectrometer to directly probe the $\mathrm{SO}_{2}$ uptake, in addition to the DRIFTS technique. Here they reported two values for $\gamma_{0, \text { BET }}$ of $(4.6 \pm 0.3) \times 10^{-6}$ and $(1.6 \pm 0.1) \times 10^{-5}$, for steady state and pulsed Knudsen cell experiments respectively.

Hence, the initial uptake coefficients for $\mathrm{SO}_{2}$ onto Saharan mineral dust reported by Ullerstam et al. (2003) differ by a factor of $\sim 3$ and are significantly smaller than the initial uptake coefficients determined by Usher et al. (2002) on the chemically similar China Loess.

This study aims to resolve this discrepancy by measuring the uptake rate of $\mathrm{SO}_{2}$ onto Saharan mineral dust in a coated wall flow tube, which allows better time resolution of uptake rates over those obtained in the DRIFTS studies discussed above. It also aims to determine the capacity of the surface to adsorb $\mathrm{SO}_{2}$ over a range of concentrations relevant to the atmosphere and provide insights into the behaviour of $\mathrm{SO}_{2}$ on the mineral dust surface. We present uptake coefficients and capacities for $\mathrm{SO}_{2}$, both alone and in the presence of $\mathrm{O}_{3}$ or water, on authentic Saharan dust collected in the Cape Verde Islands. The nature of the uptake and potential surface processes are discussed and our results compared with literature values.

\section{Experimental}

\subsection{Apparatus}

The experiments were carried out in a coated-wall flow tube coupled to a differentially pumped quadrupole mass spectrometer (ABB Extrel), shown schematically in Fig. 1. The coated-wall flow tube-mass spectrometry technique allows the determination of uptake coefficients of trace gases adsorbed onto surfaces and the observation of gas-phase products formed following heterogeneous reactions. The flow tube consisted of a horizontally mounted Pyrex glass tube (length $350 \mathrm{~mm}$, i.d. $24 \mathrm{~mm}$ ) with a thermostatted jacket to regulate the temperature as required. The dust surface was formed on the inside of a smaller Pyrex glass tube (i.d. $21 \mathrm{~mm}$, length $250 \mathrm{~mm}$ ), which fitted snugly within the larger tube, ensuring good thermal contact. The experiments were conducted at a total (flow tube) pressure of 1.5 Torr (1 Torr=1.333 hPa).

\subsection{Reactants: surface and trace gases}

The reactive surfaces for these experiments were prepared by coating the inside of the Pyrex insert with a suspension of Saharan mineral dust in ethanol. Ethanol was chosen to avoid loss of water-soluble components from the dust. Approximately $0.5 \mathrm{~g}$ of dust was mixed with $50 \mathrm{ml}$ of ethanol and shaken. Half the resulting suspension was poured into 
the insert, which was sealed at one end with Parafilm. The other end was then sealed in the same manner and the insert shaken. While holding the insert horizontally, it was turned gently until a thin, but even coating of dust was achieved. The insert was then smoothly moved to a vertical position, while still being rotated. This allowed any material, which had not adhered to the insert wall, to fall to the lower end. The Parafilm was then removed and the residual ethanol/dust collected. Unevenness in the dust coating, often observed at the ends of the insert, was removed by wiping with low lint paper towel. The insert was weighed using a precision balance after each experiment and the mass of the mineral dust coating determined.

\subsection{Measurement procedure}

The bulk flow rate of He (Messer, 99.999\%) was approximately 210 standard $\mathrm{cm}^{3} \mathrm{~min}^{-1}$, resulting in an average linear velocity of ca. $560 \mathrm{~cm} \mathrm{~s}^{-1}$. $\mathrm{SO}_{2}$ (BOC gases $99.9 \%$ ), diluted in $\mathrm{He}$, was introduced into the flow tube via a movable injector, the translation of which enabled the contact time between trace gas and surface to be varied. When humidification of the helium buffer gas was required, a measured fraction of the helium flow was passed through a water bubbler before entering the flow tube. Ozone, generated online by flowing 5-20\% $\mathrm{O}_{2}$ (Messer, 99.998\%) diluted in helium over a mercury, low pressure cold-cathode UV "Pen-Ray" lamp, could also be added to the buffer gas. The concentration of trace gases within the flow tube was measured using a quadrupole mass spectrometer. $\mathrm{SO}_{2}$ and ozone were detected at their parent ions $(\mathrm{m} / \mathrm{z}=64$ and 48 , respectively). The ozone signal was corrected for the contribution of $\mathrm{SO}_{2}$ to the observed signal at $\mathrm{m} / \mathrm{z}=48$, (the $\mathrm{SO}^{+}$fragment). Phase sensitive detection was used during a limited number of experiments, following modulation of the sample beam with a tuning fork chopper oscillating at $235 \mathrm{~Hz}$. This removed the need to subtract backgrounds from the observed signal.

2.4 Determination of uptake coefficients and reactive surface area

The pseudo first-order rate coefficient for loss to the reactive surface $k_{w}$ was calculated from the variation of the $\mathrm{SO}_{2}$ signal with injector position, according to:

$[\mathrm{C}]_{z 2}=[\mathrm{C}]_{z 1} \cdot \exp \left(-k_{w} \cdot \frac{\Delta z}{v}\right)$

where $[\mathrm{C}]_{z 1,2}$ are the trace gas concentrations at injector positions $z_{1}$ and $z_{2}, \Delta z$ represents the distance between the positions $z_{1}$ and $z_{2}$ and $v$ is the gas flow velocity in the tube. The ratio $\Delta z / v$ thus defines the gas-surface contact time. The measured value of $k_{w}$ has to be corrected (to give $k_{\text {cor }}$ ) to take into account radial and axial concentration gradients caused by interaction of the trace gas at the wall (Brown, 1978). This required knowledge of the diffusion coefficients of $\mathrm{SO}_{2}$ in both $\mathrm{He}$ and $\mathrm{H}_{2} \mathrm{O}$, which were estimated to be 391 and 90.4 Torr $\mathrm{cm}^{2} \mathrm{~s}^{-1}$, respectively, using Chapman-Enskog theory (Hirschfelder et al., 1954). The correction to $k_{w}$ due to the diffusion lay in the range $2-45 \%$.

The "geometeric" uptake coefficient (calculated using the area of the Pyrex insert exposed), could then be obtained directly from $k_{\text {cor }}$ (Howard, 1979):

$\gamma=\frac{2 \cdot r \cdot k_{\mathrm{cor}}}{\omega}$

where $r$ is the internal radius of the coated glass insert, and $\omega$ is the mean molecular velocity of the trace gas.

For a solid, the true area of the reactive surface may be many times that of the geometric surface area, owing to the presence of multiple layers of particles and/or a significant internal surface area. Multiple layers are not expected in this study as the glass insert is only sparsely covered with dust (between 0.02 and $0.5 \mathrm{mg} \mathrm{cm}^{-2}$ ), however pores in the Saharan mineral dust do provide a significant internal surface area (see Sect. 4.3). The situation is further complicated by the accessibility of the reactive surface, as slow gas-phase diffusion into a porous sample will limit the contribution of the internal surface area to the observed uptake coefficient. As such, any uptake coefficient based on the BET surface area will be a lower limit. However it is still instructive to report the uptake coefficient in this form as it allows comparison with literature values. This "BET" uptake coefficient, $\gamma_{\mathrm{BET}}$, is related to the observed "geometric" uptake coefficient by the relationship: $\gamma_{\mathrm{BET}}=A_{\text {geom }} / A_{\mathrm{BET}} \times \gamma_{\text {geom }} . A_{\text {geom }}$ and $A_{\mathrm{BET}}$ are the exposed area of the Pyrex insert and dust, respectively. $A_{\mathrm{BET}}$ is calculated from the mass of dust exposed multiplied by the BET surface area of the dust $\left(51.3 \mathrm{~m}^{2} \mathrm{~g}^{-1}\right.$ see below). Underwood et al. (2000) have shown that if this relationship is valid, then the observed uptake coefficient will be linearly dependent on the mass of substrate used. This is shown to be true in the experiments reported here (see Sect. 3.1), using dust loading on the glass insert comparable to or less than those used by Underwood et al. (2000).

The dust used in this study was collected on the Cape Verde Islands and is typical of the mineral dust transported from the Saharan source region across the Atlantic Ocean. It was not size filtered or washed. The BET surface area of the whole Cape Verde Saharan dust sample has been measured in two separate determinations as 57.3 and $43.7 \mathrm{~m}^{2} \mathrm{~g}^{-1}$. These values compare well with the two previous measurements of $50.0 \mathrm{~m}^{2} \mathrm{~g}^{-1}$ (Börensen, 2000) and $39.6 \mathrm{~m}^{2} \mathrm{~g}^{-1}$ (Hanisch and Crowley, 2003). However the surface preparation method used here may favour finer dust particles, as coarse dust grains do not adhere well to the insert wall. To see if this was the case, dust surfaces were prepared as normal, but were then washed off the insert and collected. The BET surface area of dust collected in this fashion was determined to be $51.3 \mathrm{~m}^{2} \mathrm{~g}^{-1}$. Using this figure the measured mass of the dust coating was converted to a "BET" surface area. This was then used to calculate uptake coefficients, $\gamma_{\mathrm{BET}}$, as described 


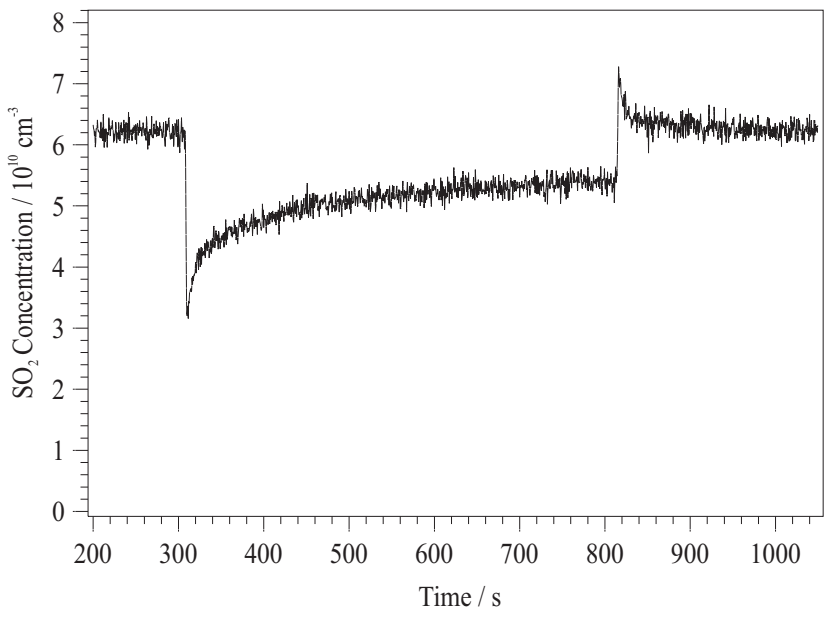

Fig. 2. Uptake of $\mathrm{SO}_{2}$ on an unhumidified Saharan dust surface at $295 \mathrm{~K}$. The injector was withdrawn $7.4 \mathrm{~cm}$ at $310 \mathrm{~s}$ to expose $\sim 6.7 \mathrm{mg}$ of dust and returned to its original position at $820 \mathrm{~s}$. Total pressure 1.5 Torr.

above. These are several orders of magnitude smaller than the uptake coefficients calculated using the geometric surface area, reflecting the large porosity of the dust samples used in these experiments. The uptake of $\mathrm{SO}_{2}$ onto Saharan mineral dust has been studied at both room temperature ( $297 \pm 2 \mathrm{~K})$ and $258 \mathrm{~K}$, with and without the presence of water and of ozone.

\section{Results}

Figure 2 shows data taken at $295 \mathrm{~K}$, using unhumidified Saharan dust and an initial $\mathrm{SO}_{2}$ concentration of $6.3 \times 10^{10}$ molecule $\mathrm{cm}^{-3}$. Over the timescale of the experiments the $\mathrm{SO}_{2}$ signal drifted slightly (typically $2-3 \%$ over $1000 \mathrm{~s})$. This drift occurred in most experiments, but was found to be roughly linear with time and was corrected for. After $\sim 310 \mathrm{~s}$, the injector was withdrawn rapidly by $7.4 \mathrm{~cm}$, exposing the trace gas to the mineral dust. For this sample $7.4 \mathrm{~cm}$ corresponded to the exposure of $6.7 \mathrm{mg}$ of dust, or $0.34 \mathrm{~m}^{2}$ of reactive surface. The signal at $\mathrm{m} / \mathrm{z}=64$ falls rapidly as the $\mathrm{SO}_{2}$ is taken up onto the surface. The maximum uptake coefficients were determined from the signal change observed in the first few seconds following withdrawal of the injector and are designated initial uptake coefficients, $\gamma_{0}$. During the next $\sim 510 \mathrm{~s}$ the $\mathrm{SO}_{2}$ signal increases continuously and the uptake coefficient simultaneously decreases. It was not possible to allow the experiments to continue long enough to ensure that the $\mathrm{SO}_{2}$ signal returned to its initial level, because of the signal drift mentioned above. In Fig. 2 the $\mathrm{SO}_{2}$ signal has returned to within $10 \%$ of its initial level when the exposure was ended. However in the case of high initial gas-phase $\mathrm{SO}_{2}$ concentrations onto low dust

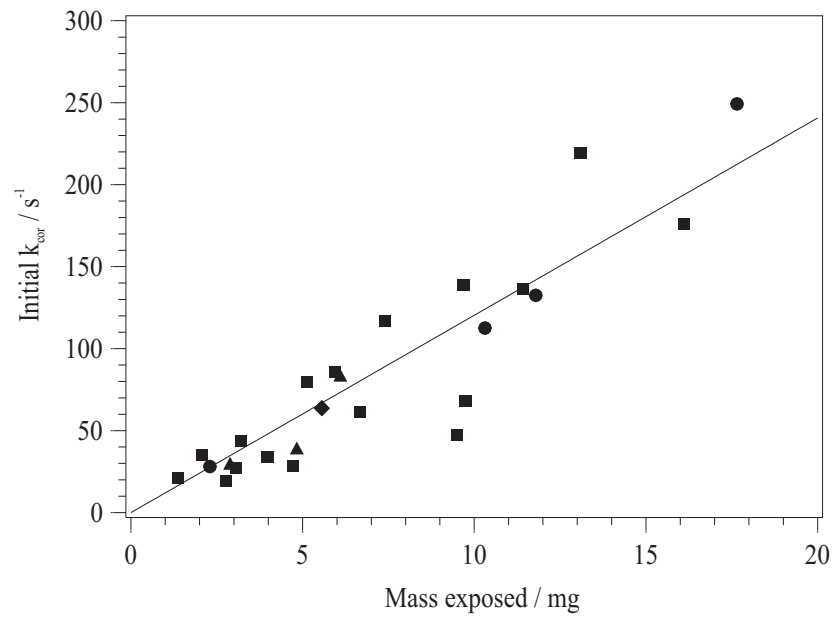

Fig. 3. Variation of the corrected initial first order loss coefficient with mineral dust mass loading. Squares: room temperature not humidified; circles: $258 \mathrm{~K}$ not humidified; triangles: $258 \mathrm{~K}$, humidified; diamond: ozone present in the carrier gas at a concentration of $\sim 10^{13}$ molecule $\mathrm{cm}^{-3}$.

loadings the signal returned to within $2 \%$ of its initial value (see first uptake in Fig. 5).

At $\sim 820$ s the injector was returned to its original position and $\mathrm{SO}_{2}$ was released back to the gas-phase, causing the observed peak. The $\mathrm{SO}_{2}$ signal returned to its initial value in about $40 \mathrm{~s}$. In every experiment the number of $\mathrm{SO}_{2}$ molecules released was less than the number of molecules taken up. No detectable $\mathrm{CO}_{2}(\mathrm{~m} / \mathrm{z}=44)$ was evolved during the uptake experiments.

Uptake experiments were also performed onto the bare glass insert, but no change in the $\mathrm{SO}_{2}$ signal was observed upon withdrawal of the injector. From the noise on the signal an upper limit of $\sim 1 \times 10^{-7}$ could be estimated for the uptake coefficient of $\mathrm{SO}_{2}$ to Pyrex. This is too small to affect the experiments in the presence of mineral dust.

\subsection{Initial uptake coefficient}

\subsubsection{Dependence on dust mass}

Figure 3 shows how the corrected first order loss coefficient, $k_{\text {cor }}$, varies with mass of dust exposed. The values are derived from the initial drop in the signal on $m / z=64$ and, although there is considerable scatter, show a linear relationship to the mass loading as it is varied over an order of magnitude. The plot includes all the available data, taken over the range of conditions studied. The precision of the balance used to weigh the dust samples was $\pm 1 \mathrm{mg}$. This value propagates (not all the sample was exposed during an experiment) to an error of between $\sim 25 \%$ and $\sim 5 \%$ in the mass exposed in Fig. 3, at the lowest and highest masses respectively. 


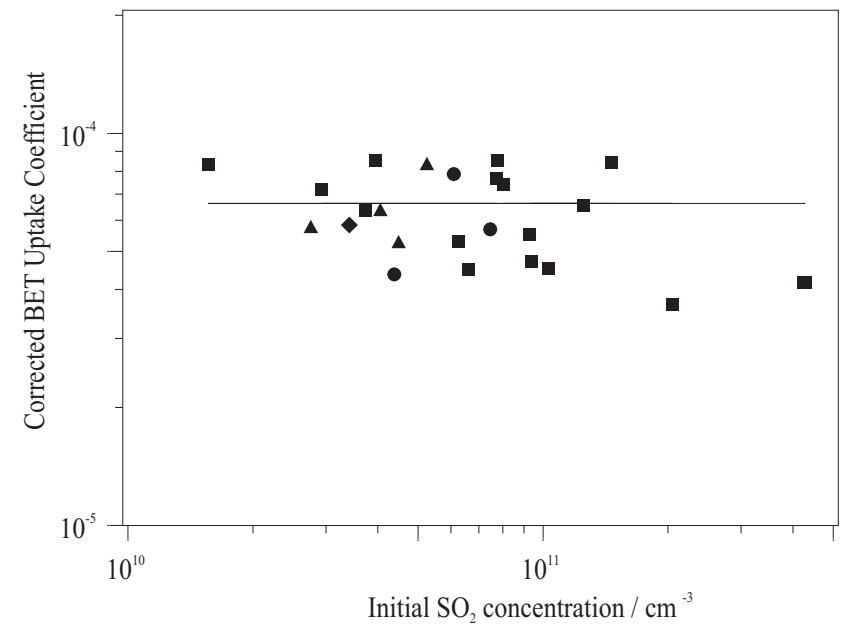

Fig. 4. Corrected initial (BET) uptake coefficients plotted as a function of initial $\mathrm{SO}_{2}$ concentration. Squares: room temperature not humidified; circles: $258 \mathrm{~K}$ not humidified; triangles: $258 \mathrm{~K}$, humidified; diamond: ozone present in the carrier gas at a concentration of $\sim 10^{13}$ molecule $\mathrm{cm}^{-3}$. The line represents the average values for unhumidified surfaces at room temperature.

Table 1. Summary of the initial uptake coefficients, $\gamma_{0, \mathrm{BET}}$, of $\mathrm{SO}_{2}$ on Saharan dust. The number of experiments is shown in brackets.

\begin{tabular}{ll}
\hline Temperature/K & Initial BET Uptake Coefficient $/ 10^{-5}$ \\
\hline 298 & $6.6 \pm 0.8(18)$ \\
258 (Dry) & $6.4 \pm 0.7(4)$ \\
258 (Humidified) & $6.0 \pm 1.0(3)$ \\
\hline
\end{tabular}

3.1.2 Dependence on initial $\mathrm{SO}_{2}$ concentration and flow conditions

The initial concentration of $\mathrm{SO}_{2}$ was varied over the range $(2-40) \times 10^{10}$ molecule $\mathrm{cm}^{-3}$, to determine if the initial gasphase concentration of $\mathrm{SO}_{2}$ used affected the initial uptake coefficient. Figure 4 shows the corrected initial BET uptake coefficients plotted as a function of the initial $\mathrm{SO}_{2}$ concentration. No significant dependence on the initial concentration was seen for the majority of experiments, although higher initial concentrations of $(\sim 21-43) \times 10^{10}$ molecule $\mathrm{cm}^{-3}$ gave systematically lower uptake coefficients. Such an effect is expected if the uptake coefficient is time dependent due to saturation/removal of surface sites.

The measured uptake coefficient on a fresh surface was not a function of the distance the injector was withdrawn, or the linear velocity of the buffer gas.

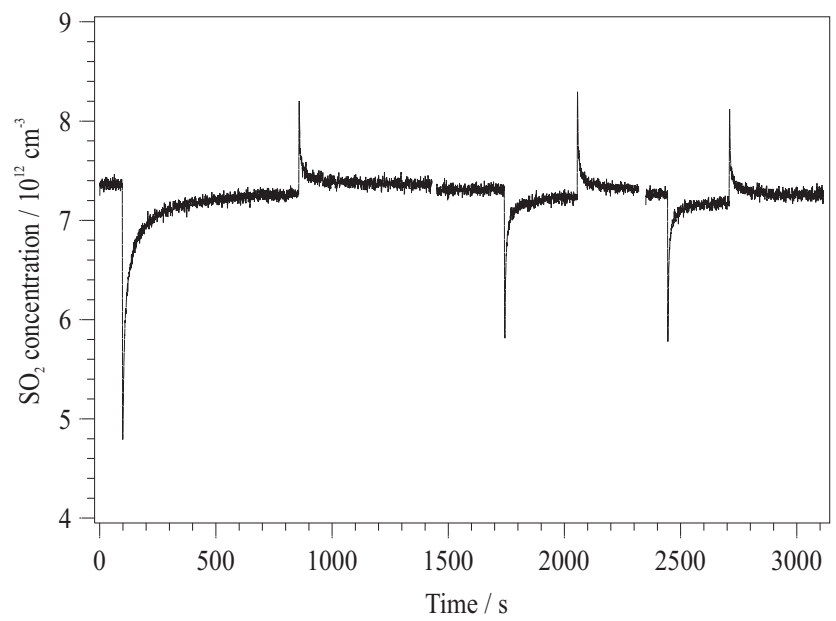

Fig. 5. Multiple uptakes onto the same dust sample. The injector was repeatedly withdrawn $6.9 \mathrm{~cm}$ to expose $\sim 15 \mathrm{mg}$ of dust. Total pressure 1.5 Torr.

\subsubsection{Dependence on temperature, relative humidity and presence of ozone}

Table 1 shows the results of experiments performed onto unhumidified dust surfaces at 258 and $298 \mathrm{~K}$. Within error, there was no difference between the initial uptake coefficients determined at these two temperatures.

A set of experiments was performed at room temperature in the presence of excess $\mathrm{O}_{3}$. A continuous flow of ozone $\left(\sim 10^{13}\right.$ molecule $\left.\mathrm{cm}^{-3}\right)$ was mixed into the helium buffer gas, upstream of the reactor and passed over the dust surface. Once the $\mathrm{O}_{3}$ signal, measured at its parent peak $(\mathrm{m} / \mathrm{z}=48)$, was stable $\mathrm{SO}_{2}$ was added through the sliding injector and the injector withdrawn. No changes in the measured initial uptake coefficient of $\mathrm{SO}_{2}$ were observed under these conditions, suggesting that the uptake process is not influenced by the presence of $\mathrm{O}_{3}$.

The influence of water vapour on the interaction of $\mathrm{SO}_{2}$ with mineral dust was investigated. A further set of experiments was performed at $258 \mathrm{~K}$, this time humidifying the helium buffer gas and therefore the dust surface, before and during the $\mathrm{SO}_{2}$ uptake. In these experiments a partial pressure of water vapour of 0.33 Torr was present in the reactor. This corresponds to a relative humidity of $27 \%$ at $258 \mathrm{~K}$.

Figure 4 displays the data from all the experiments carried out in this study and shows that the presence of water or ozone did not, within the fairly large statistical error, affect the measured initial uptake coefficient. These data are summarised in Table 1.

\subsubsection{Multiple exposure of a dust surface}

A multiple exposure experiment is shown in Fig. 5. Uptakes onto previously exposed surfaces (the second and third uptake cycles in Fig. 5) were also time-dependent, but differed 


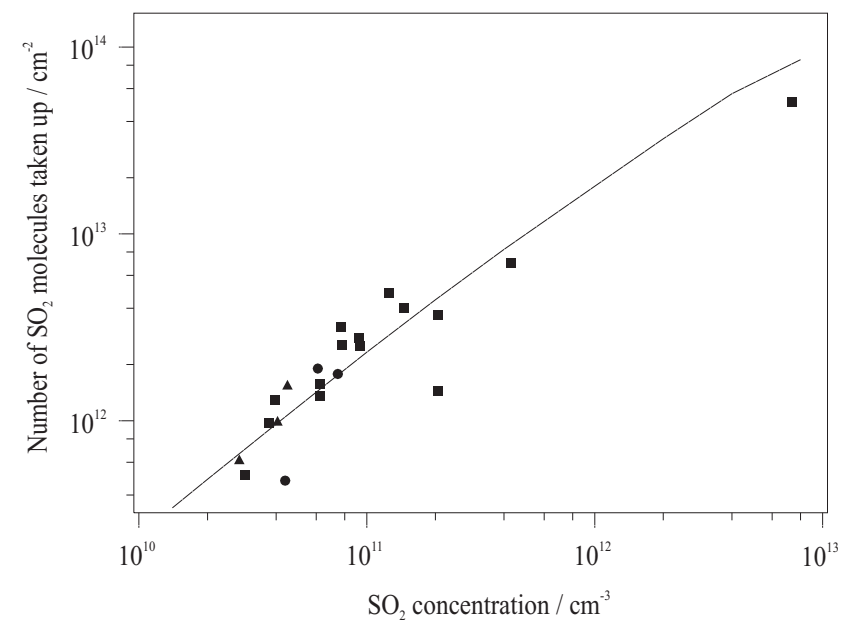

Fig. 6. Calculated surface coverage, following uptake of $\mathrm{SO}_{2}$ onto fresh dust surfaces plotted as a function of initial $\mathrm{SO}_{2}$ concentration. Squares: $\mathrm{T}=295 \mathrm{~K}, 0 \%$ relative humidity; circles: $\mathrm{T}=258 \mathrm{~K}$, $0 \%$ relativity humidity; triangles: $\mathrm{T}=258 \mathrm{~K}, 27 \%$ relative humidity; diamond: $\mathrm{T}=295 \mathrm{~K}, 0 \%$ relative humidity, ozone present in the carrier gas at a concentration of $\sim 10^{13}$ molecule $\mathrm{cm}^{-3}$. The line is the predicted amount of $\mathrm{SO}_{2}$ taken up per unit area from the model described in Sect. 4.3.

from the first uptake/desorption cycle in several ways. The initial uptake coefficient on pre-exposed surfaces was $\sim 50 \%$ smaller than onto a fresh surface, but did not decrease further, irrespective of the number of surface exposures. Attempts were made to reactivate the surface by leaving the sample under 1 bar of helium overnight, or flowing ozone $\left(\sim 1 \times 10^{13}\right.$ molecule $\left.\mathrm{cm}^{-3}\right)$ over the dust for $\sim 1 \mathrm{~h}$ between two $\mathrm{SO}_{2}$ exposures. These procedures did not lead to any recovery or reduction in the initial uptake coefficient.

\section{2 $\mathrm{SO}_{2}$ adsorbed onto the dust surface}

The $\mathrm{SO}_{2}$ source was not sufficiently stable over the required timescale for saturation of the dust surface to be achieved under the experimental conditions used. Here we report the amount of gas-phase $\mathrm{SO}_{2}$ taken up per unit area of mineral dust surface after $200 \mathrm{~s}$, during each experiment. This allows a comparison to be made between the various experimental conditions used.

The total net molecules adsorbed during the first $200 \mathrm{~s}$ of an exposure was calculated by summing the loss in the calibrated mass spectrometer signal, $\sum_{t=0}^{200}\left(N_{0}-N_{t}\right)$, where $N_{0}$ is the initial signal and $N_{t}$ is the value of the signal at time $t$ and multiplying this sum (in molecule $\mathrm{cm}^{-3} \mathrm{~s}$ ) by the flow rate $\left(\mathrm{cm}^{3} \mathrm{~s}^{-1}\right)$. The amount of $\mathrm{SO}_{2}$ taken up per $\mathrm{cm}^{2}$ of dust was then calculated by dividing the total net molecules taken up by the BET surface area of the exposed dust.

The number of $\mathrm{SO}_{2}$ molecules released per unit area, once the injector was returned to its original position, was deter-

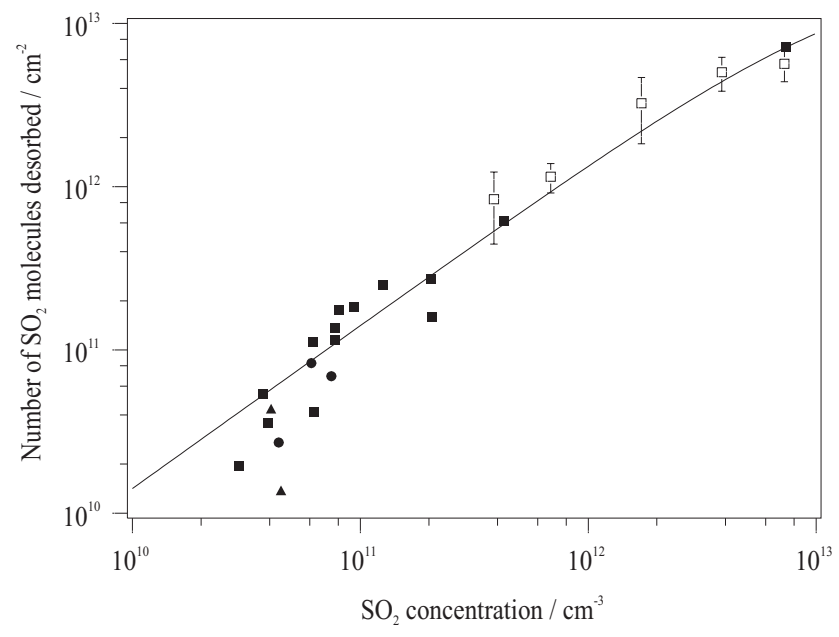

Fig. 7. Molecules of $\mathrm{SO}_{2}$ released into the gas-phase, following exposure of a mineral dust surface, plotted as a function of initial $\mathrm{SO}_{2}$ concentration. Squares: $\mathrm{T}=295 \mathrm{~K}, 0 \%$ relative humidity; circles: $\mathrm{T}=258 \mathrm{~K}, 0 \%$ relativity humidity; triangles: $\mathrm{T}=258 \mathrm{~K}, 27 \%$ relative humidity; diamond: $\mathrm{T}=295 \mathrm{~K}, 0 \%$ relative humidity, ozone present in the carrier gas at a concentration of $\sim 10^{13}$ molecule $\mathrm{cm}^{-3}$; solid symbols: uptake onto fresh surfaces; open symbols: repeated exposure of the same surface. The line is a fit to the data using a single site Langmuir isotherm.

mined by summing under the desorption curve, converting the value obtained to a flux and then dividing by the BET surface area of the exposed dust.

\subsection{1 $\mathrm{SO}_{2}$ adsorbed per unit area}

Figure 6 shows the variation of the net number of molecules of $\mathrm{SO}_{2}$ taken up per $\mathrm{cm}^{2}$ after an exposure time of $200 \mathrm{~s}$, on previously unexposed Saharan mineral dust as a function of $\mathrm{SO}_{2}$ initial concentration. The solid squares show results from experiments at room temperature. The surface coverage increases non-linearly by over two orders as the concentration increases by nearly 3 orders of magnitude. Results for unhumidified (circles) and humidified (triangles) surfaces at $258 \mathrm{~K}$ are also shown. All these points lie within the scatter on the data at room temperature and demonstrate that the amount of $\mathrm{SO}_{2}$ taken up per unit area is not affected by temperature or humidity over the range of conditions studied. Uptake experiments were also carried out in the presence of $\sim 10^{13}$ molecule $\mathrm{cm}^{-3}$ ozone, but the surface was only exposed for around $50 \mathrm{~s}$. The amount of $\mathrm{SO}_{2}$ taken up per unit area after $50 \mathrm{~s}$ in these experiments was the same within error as for experiments (after $50 \mathrm{~s}$ ) without added ozone with the same initial $\mathrm{SO}_{2}$ concentration. The line in Fig. 6 is the modelled variation with initial $\mathrm{SO}_{2}$ concentration of the $\mathrm{SO}_{2}$ taken up per $\mathrm{cm}^{2}$ after $200 \mathrm{~s}$ exposure (see Sect. 4.3). 


\subsection{2 $\mathrm{SO}_{2}$ released per unit area}

Figure 7 shows the variation in the number of molecules of $\mathrm{SO}_{2}$ per unit area released back into the gas-phase when the injector was returned to its original position. The amount of $\mathrm{SO}_{2}$ released is less than the amount taken up for any given concentration of $\mathrm{SO}_{2}$. The ratio of molecules adsorbed (after $200 \mathrm{~s}$ ) to molecules released for a given experiment is a function of $\mathrm{SO}_{2}$ concentration, falling from ca 50 at $\left[\mathrm{SO}_{2}\right]=3 \times 10^{10}$ molecule $\mathrm{cm}^{-3}$ to ca 7 at $\left[\mathrm{SO}_{2}\right]=7 \times 10^{12}$ molecule $\mathrm{cm}^{-3}$. No significant trend in this ratio with respect to the duration of the surface exposure was observed. The amount of $\mathrm{SO}_{2}$ released was not significantly lower when water was present (triangles). In the presence of $\mathrm{O}_{3}$ very little $\mathrm{SO}_{2}$ was released back into the gas-phase.

Most of the data in Fig. 7 show results from surfaces that were exposed only once. However, the open squares show surface coverages of reversibly adsorbed $\mathrm{SO}_{2}$ on a dust surface that was repeatedly exposed to a range of initial concentrations of $\mathrm{SO}_{2}$. The data points represent the average of at least three uptake cycles and are consistent with the results from experiments involving previously unexposed surfaces.

\section{Discussion}

\subsection{Initial uptakes onto fresh dust}

The value for $\gamma_{0, \mathrm{BET}}=(6.6 \pm 0.8) \times 10^{-5}$ measured in this study is in good agreement with the value of $(4 \pm 2) \times 10^{-5}$ reported by Usher et al. (2002) for the uptake of $\mathrm{SO}_{2}$ onto China Loess. Given that the components of China Loess are similar to those found in Saharan dust, albeit in different proportions, this similarity in the $\mathrm{SO}_{2}$ uptake coefficients is perhaps not surprising. Usher et al also studied the interaction of $\mathrm{SO}_{2}$ with mineral oxides, which in the form of aluminium silicate clays, are components of both Saharan mineral dust and China Loess. The initial uptake coefficients for $\mathrm{SO}_{2}$ onto these oxides was typically $\sim 1 \times 10^{-4}$. The magnitude of the initial uptake coefficient reported here is consistent with these values, given that approximately 50\% (Hanisch and Crowley, 2003) of the Saharan dust sample is unreactive $\mathrm{SiO}_{2}\left(\gamma_{\mathrm{BET}}<1 \times 10^{-7}\right)$ and that the metal oxides may be a poor proxy for clays.

The value for $\gamma_{0, \mathrm{BET}}=(6.6 \pm 0.8) \times 10^{-5}$ measured in this study is significantly larger than the values for $\gamma_{0, \mathrm{BET}}=(4.6 \pm 0.3) \times 10^{-6}$ and $(1.6 \pm 0.1) \times 10^{-5}$ reported by Ullerstam et al. $(2002,2003)$. One difference between this study and those conducted earlier is the concentrations of $\mathrm{SO}_{2}$ used, with concentrations in this work typically 10-100 times smaller than Ullerstam et al. $(2002,2003)$. A further difference lies in the preparation of the dust sample. Here untreated samples were used, deposited from a suspension in ethanol onto the support, whereas Ullerstam et al. (2002, 2003) spray deposited their samples and then baked them to remove much of the adsorbed water. This could cause a reduction in porosity in the clay components of the dust as water is driven from the interstitial layers, such that the actual BET surface area of the baked sample is less than the unbaked sample. This would then lead to an underestimate of the BET uptake coefficient.

\subsection{Adsorbed $\mathrm{SO}_{2}$ on dust surfaces}

The capacity of the dust surface to adsorb $\mathrm{SO}_{2}$ and the nature of the $\mathrm{SO}_{2}$-surface interaction are required if the importance of $\mathrm{SO}_{2}$ processing on mineral dust in the atmosphere is to be established.

The presence of a desorption peak, once surface exposure ends, shows that the uptake of $\mathrm{SO}_{2}$ onto the dust particles is partially reversible. The reversible nature of the uptake of these molecules implies that they are physisorbed to the dust surface. A single site Langmuir adsorption isotherm of the form:

$x_{p}=\frac{x_{m} k\left[\mathrm{SO}_{2}\right]}{1+k\left[\mathrm{SO}_{2}\right]}$

was used to describe the data in Fig. 7, where $x_{p}$ is the surface coverage (molecule $\mathrm{cm}^{-2}$ ) at concentration $\left[\mathrm{SO}_{2}\right]$ (molecule $\mathrm{cm}^{-3}$ ) and $k$ is the Langmuir constant. From the fit to the data, the maximum surface coverage, $x_{m}$, for physisorption was found to be $(2 \pm 1) \times 10^{13}$ molecule $\mathrm{cm}^{-2}$ and a value of $(6 \pm 2) \times 10^{-14}$ molecule ${ }^{-1} \mathrm{~cm}^{3}$ was determined for the Langmuir constant. The quoted errors are $2 \sigma$ from the fit.

The amount of $\mathrm{SO}_{2}$ adsorbed during the first $200 \mathrm{~s}$ of the adsorption phase on a fresh dust surface (Fig. 6) is larger than the amount desorbed from the same surface and show that most of the adsorbed $\mathrm{SO}_{2}$ is irreversibly taken up. At the highest concentrations $\sim 86 \%$ of the $\mathrm{SO}_{2}$ was irreversibly bound, rising to $\sim 98 \%$ at the lowest. These molecules are likely to be chemisorbed to the dust surface.

Assuming that ozone molecules are adsorbed on the dust surface, the observation that the amount of reversibly adsorbed $\mathrm{SO}_{2}$ is reduced in the presence of ozone implies competition for the sites at which physical adsorption occurs. On the other hand the presence of $\mathrm{O}_{3}$ did not significantly affect the amount of chemisorbed $\mathrm{SO}_{2}$. This shows that either $\mathrm{O}_{3}$ binds to different sites from the $\mathrm{SO}_{2}$ or is only weakly bound and is displaced by the $\mathrm{SO}_{2}$. Evidence that ozone is adsorbed onto the dust surface is summarised by Usher et al. (2003). The addition of $\sim 1 \times 10^{16}$ molecule $\mathrm{cm}^{-3}$ of water to the carrier gas did not, within error, affect the measured surface coverage at a particular gas-phase $\mathrm{SO}_{2}$ concentration.

Similar adsorption/desorption behaviour (in the absence of water) has been observed in studies of the interaction of $\mathrm{SO}_{2}$ with metal oxides. Goodman et al. (2001) showed that only $10 \%$ of adsorbed $\mathrm{SO}_{2}$ on $\alpha-\mathrm{Al}_{2} \mathrm{O}_{3}$ and $\mathrm{MgO}$ surfaces was lost when the sample vessel was evacuated. These authors observed, using FTIR spectroscopy, the formation of weakly bound molecular $\mathrm{SO}_{2}$, and ionic sulphite and bisulphite on 
the surface of $\mathrm{Al}_{2} \mathrm{O}_{3}$ and $\mathrm{MgO}$ particles and concluded that chemisorption occurred for $\mathrm{SO}_{2}$ at basic surface sites, whilst physisorption occurred at acidic sites. Surface bound hydroxyl groups or lattice oxygen atoms were proposed as the basic sites, whereas surface bound hydroxyl groups have also been observed on Saharan mineral dust (Ullerstam et al., 2002), but these authors propose that the $\mathrm{SO}_{2}$ is only weakly bound to these sites.

Ullerstam et al. (2002) report a surface saturation of $2 \times 10^{19}$ sulphate ions $\mathrm{g}^{-1}$, in the presence of ozone. This is equivalent to a surface coverage of $4 \times 10^{13}$ molecule $\mathrm{cm}^{-2}$, based on the BET surface area. Goodman et al. (2001) report values for the maximum surface coverage of $\sim 1.5 \times 10^{14}$ molecule $\mathrm{cm}^{-2}$ for $\mathrm{Al}_{2} \mathrm{O}_{3}$ and a lower limit of $\sim 4 \times 10^{14}$ molecule $\mathrm{cm}^{-2}$ for $\mathrm{MgO}$. Coverages of $2.5 \times 10^{14}$ and $1.7 \times 10^{15}$ molecule $\mathrm{cm}^{-2}$ for $\mathrm{Al}_{2} \mathrm{O}_{3}$ and $\mathrm{MgO}$, respectively, in the presence of oxygen, can also be derived from reported saturation sulphate ion surface concentrations (Judeikis et al., 1978). In the current work the largest amount of $\mathrm{SO}_{2}$ irreversibly taken up per unit area was $\sim 8 \times 10^{13}$ molecule $\mathrm{cm}^{-2}$, which is consistent with these maximum surface coverages, given that approximately $50 \%$ (Hanisch and Crowley, 2003) of the Saharan dust sample is unreactive $\mathrm{SiO}_{2}$ and that Saharan mineral dust contains clays containing metal oxides, rather than metal oxides themselves.

\subsection{Uptake mechanism and model}

Insights into the adsorption mechanism for $\mathrm{SO}_{2}$ onto Saharan mineral dust may be deduced from the time dependence and the adsorption/desorption behaviour observed in the flow tube experiments. The initial rapid return of the $\mathrm{SO}_{2}$ signal towards its initial value following exposure could be caused by the rapid filling of surface sites, whereas the slow return at longer times could be caused by another surface process.

One possibility for this surface process is that the $\mathrm{SO}_{2}$, once adsorbed onto the dust surface, is reacting with surface adsorbed species or a different surface site, following a Langmuir-Hinshelwood type mechanism. Indeed, $\mathrm{SO}_{2}$ has been observed to be oxidised to sulphate on baked Saharan mineral dust in the absence of added oxidants (Ullerstam et al., 2002). Ammann et al. (2003) have recently derived an expression for the observed reactive uptake coefficient of a gas-phase molecule due to surface reaction with a surface bound reactant and modelled the gas-phase time dependence of this gas-phase molecule. This time dependence is similar to that seen here, that is fast initial recovery of the $\mathrm{SO}_{2}$ signal followed by a slow recovery at longer times.

A further possibility is that, following adsorption of $\mathrm{SO}_{2}$ onto the mineral dust surface, diffusion occurs into pores within the dust. If the dust particles are assumed to be spherical, have a density of $2.8 \mathrm{~g} \mathrm{~cm}^{-3}$ and a diameter of $3 \mu \mathrm{m}$ then the outer surface area is a factor of $\sim 80$ smaller than the BET surface area. This is also shown by the surface area mea- surements which indicate that a significant proportion of the measured BET surface area of the Saharan dust lies within pores, having an average pore diameter of $\sim 50 \AA$.

A kinetic model has been developed using the numerical integration package FACSIMILE (Curtis and Sweetenham, 1987) to investigate the uptake of $\mathrm{SO}_{2}$ onto mineral dust in a flow tube and was adapted from a model used to study the interaction of acidic gases with ice surfaces (Cox et al., 2005). The flow tube is divided into 20 cells, within which plug flow conditions are assumed. At the beginning of a model run gas-phase $\mathrm{SO}_{2}$ is added to the first cell at a rate determined by its concentration, the flow velocity and the tube radius. The gas-phase $\mathrm{SO}_{2}$ interacts with the cell walls by adsorption/desorption, or is transported to the next cell by the flow and axial diffusion. These processes are repeated in the next and following cells until the end of the flow tube. Once on the dust surface $\mathrm{SO}_{2}$ molecules can desorb, react with a surface species or site or diffuse into the pores, where again the $\mathrm{SO}_{2}$ can react with a surface species or site. The following mechanism was used:

$\mathrm{SO}_{2(\mathrm{~g})}+\mathrm{S} \Leftrightarrow \mathrm{SO}_{2 \text { (ads) }} \quad k_{\text {ads }} / k_{\text {des }}$
$\mathrm{SO}_{2(\text { ads })}+\mathrm{R}_{1} \rightarrow$ Product $\quad k_{s}$
$\mathrm{SO}_{2 \text { (ads) }} \rightarrow \mathrm{SO}_{2 \text { (pore) }} \quad k_{\text {diff }}$
$\mathrm{SO}_{2 \text { (pore) }}+\mathrm{R}_{2} \rightarrow$ Product $\quad k_{s}$

where $\mathrm{SO}_{2(\mathrm{~g})}, \mathrm{SO}_{2(\text { ads })}$ and $\mathrm{SO}_{2(\text { pore })}$ are the gas-phase concentration, the surface concentration and the "concentration" of $\mathrm{SO}_{2}$ in the pores, respectively. $\mathrm{R}_{1}$ (on the dust surface) and $\mathrm{R}_{2}$ (in the pores) are surface bound species or sites. Here all concentrations (including surface site concentrations) are in units of molecule $\mathrm{cm}^{-3}$, i.e. number density per unit volume of the flow tube. $k_{s}$ is the 2 nd order rate coefficient for the reaction of these species or sites with surface bound $\mathrm{SO}_{2} . k_{\mathrm{ads}}$ is the rate coefficient for single-site adsorption and is defined as

$k_{\mathrm{ads}}=\frac{\gamma_{0, \mathrm{BET}} \omega}{4} \times \frac{2}{r} \times \frac{A}{S_{0}}\left(\mathrm{~cm}^{3}\right.$ molecule $\left.{ }^{-1} \mathrm{~s}^{-1}\right)$

where $\gamma_{0, \mathrm{BET}}$ is the initial BET uptake coefficient, $\omega$ is the mean speed, A the ratio $A_{\mathrm{BET}} / A_{\text {geom }}$ and $(2 / r)$ the geometric surface/volume ratio of the flow tube, radius $r$. Division by $S_{0}$, the assumed initial number of sites, is necessary to convert the surface concentrations to dimensionless surface coverages. An initial density of sites of $\sim 4 \times 10^{13}$ molecule $\mathrm{cm}^{-3}$ was used, determined by converting the maximum surface coverage for physisorption of $\sim 2 \times 10^{13}$ molecule $\mathrm{cm}^{-2}$, found in Sect. 4.2, to a number density per unit volume. The ratio A was necessary to reflect the different surface loadings used in the experiments. The product $\gamma_{0, \mathrm{BET}} \times A$ is equal to the geometric initial uptake coefficient. This quantity was used in the model runs. 


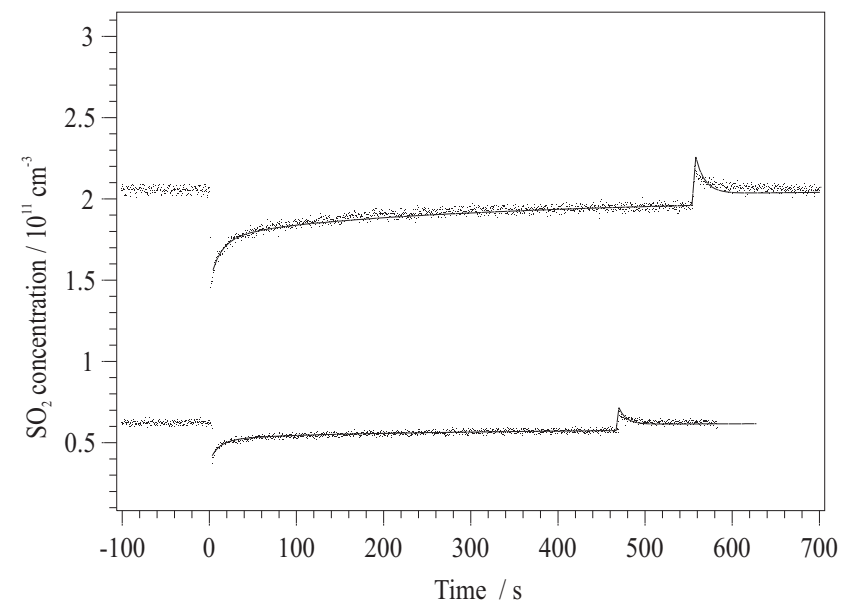

Fig. 8. Comparison of experimental (dots) and simulated (lines) data. The model parameters used are given in Table 2 .

$k_{\text {des }}$ is the rate coefficient for desorption from the surface and is defined as

$k_{\mathrm{des}}=\frac{k_{\mathrm{ads}}}{K_{\mathrm{eqm}}}\left(\mathrm{s}^{-1}\right)$

where $K_{\text {eqm }}$ is the Langmuir equilibrium constant. A value of $1 \times 10^{-13}$ molecule ${ }^{-1} \mathrm{~cm}^{3}$ was used, consistent with the equilibrium constant of $6 \times 10^{-14}$ molecule ${ }^{-1} \mathrm{~cm}^{3}$ determined from the experimental data, as described above. Diffusion into pores in the dust was approximated by diffusion into a bulk film. This was represented as a first order process, with a time-dependent rate coefficient

$k_{\mathrm{diff}}=\frac{1}{L} \times\left(\frac{D_{s}}{\pi t}\right)^{0.5}\left(\mathrm{~s}^{-1}\right)$

where $L$ is the film depth and $D_{s}$ is the bulk diffusion coefficient. This expression derives from the solution of the diffusion equation for Fick's Law with a specified mean diffusion depth $L$. More explicit models of pore diffusion do exist and have been used successfully to correct uptake coefficients in a number of studies, but these are either concerned with time independent uptake (Keyser et al., 1991; Timonen et al., 1994) or uptake into multiple layers of particles (Goodman et al., 2001). $D_{s}^{0.5} / L$ was used as an adjustable parameter.

Flow tube experiments were modelled as follows. The gasphase concentration of $\mathrm{SO}_{2}$ in the first cell was set to the initial concentration used in the experiment, mimicking the effect of withdrawing the injector. The gas-phase $\mathrm{SO}_{2}$ was then transported through the cells, interacting with the dust surface. The modelled $\mathrm{SO}_{2}$ concentration in the final cell was then compared with the experimental data. Model parameters such as flow speed, exposed dust area, temperature and exposure duration were matched to the experiments. Others, such as the number of surface sites, the Langmuir constant
Table 2. Model parameters used in Figs. $8 \mathrm{a}$ and b.

\begin{tabular}{lll}
\hline Parameter & Fig. 8a & Fig. $8 \mathrm{~b}$ \\
\hline Temp $/ K$ & 295 & 295 \\
Linear velocity $/ \mathrm{cm} \mathrm{s}^{-1}$ & 821 & 609 \\
{$\left[\mathrm{SO}_{2}\right]_{\text {init }} /$ molecule cm $^{-3}$} & $6.25 \times 10^{10}$ & $2.06 \times 10^{11}$ \\
$\gamma_{0, \text { geom }}$ & $3.6 \times 10^{-3}$ & $1.8 \times 10^{-3}$ \\
$A_{\mathrm{BET}} / A_{\text {geom }} / \mathrm{cm}^{2} \mathrm{~cm}^{-2}$ & 73.6 & 50.3 \\
$S_{0} / \mathrm{molecule} \mathrm{cm}^{-3}$ & & $4.4 \times 10^{13}$ \\
$K_{\text {eqm }} / \mathrm{molecule}^{-1} \mathrm{~cm}^{3}$ & & $1 \times 10^{-13}$ \\
$k_{\text {ads }} / \mathrm{cm}^{3}$ molecule $^{-1} \mathrm{~s}^{-1}$ & & $\gamma_{0} \omega / 2 S_{0}$ \\
$k_{\text {des }} / \mathrm{s}^{-1}$ & $k_{a} / K_{\text {eqm }}$ \\
$k_{S} / \mathrm{cm}^{3}$ molecule $^{-1} \mathrm{~s}^{-1}$ & $5.9 \times 10^{-15}$ \\
$\sqrt{ } D_{\mathrm{SO}_{2}} / L / s^{-0.5}$ & & 0.393 \\
$\mathrm{R}_{1} / \mathrm{molecule}^{-3}$ & & $2.4 \times 10^{12}$ \\
$\mathrm{R}_{2} / \mathrm{molecule}^{-3} \mathrm{~cm}^{-3}$ & & $4.9 \times 10^{13}$ \\
\hline
\end{tabular}

for adsorption/desorption and the total concentration of reaction partners $\mathrm{R}\left(=\mathrm{R}_{1}+\mathrm{R}_{2}\right)$ were set to values consistent with the values discussed in Sect. 4.2. The reaction rate constant $k_{s}$ and the diffusion parameter $D_{s}^{0.5} / L$ were freely varied, as was the distribution of the density of surface reactants/sites between $R_{1}$ and $R_{2}$. The best agreement between model and experimental data, when considering multiple experiments, was achieved when $\sim 95 \%$ of the reacting species/sites $R$ resided in the pores (as $\mathrm{R}_{2}$ ) and could only be accessed via diffusion into the pores of bound $\mathrm{SO}_{2}$ molecules from the dust surface.

Figures $8 \mathrm{a}$ and $\mathrm{b}$ compare the output of the model with data from two experiments, with different initial gas-phase $\mathrm{SO}_{2}$ concentrations and surface loadings. Model parameters are given in Table 2. Parameters $S_{0}, \mathrm{R}_{1}$ and $\mathrm{R}_{2}$ were multiplied by (and $k_{s}$ divided by) the ratio $A_{\mathrm{BET}} / A_{\text {geom }}$ in each case to reflect the different surface loadings of dust. A good agreement between the model output and experimental data is achieved for both the adsorption and desorption sections of the experiments. Further experiments, under different conditions of initial $\mathrm{SO}_{2}$ concentration and dust loading, have also been modelled. The same values for the model parameters given in Table 2 gave a reasonable fit to these experiments.

The model was also used to predict the dependence of the amount of $\mathrm{SO}_{2}$ per unit area after $200 \mathrm{~s}$ exposure on the initial $\mathrm{SO}_{2}$ concentration. This dependence is plotted as a line in Fig. 6. There is good agreement with the measured values. This indicates that the model is reasonable, and that the dependence observed in Fig. 6 is a kinetic effect.

The relationship between the integrated amounts of $\mathrm{SO}_{2}$ taken up per unit area and the initial $\mathrm{SO}_{2}$ gas-phase concentration is non-linear because the mechanism depends on 2 reactions. At low surface coverages reaction (R2) dominates over diffusion into the pores. As the surface concentration increases, reactant/site $R_{1}$ is depleted and diffusion into the 
pores drives the continued uptake. The switch between the regimes will occur after different times depending upon the initial $\mathrm{SO}_{2}$ concentration.

\section{Atmospheric implications}

The lifetime for removal of $\mathrm{SO}_{2}$ via heterogeneous reaction on dust is given by $\tau_{\text {het }}=4 / \gamma \omega A$, where $A$ is the surface area density of the dust, $\omega$ is the mean molecular speed and $\gamma$ is the uptake coefficient. In the experiments performed in this work, using atmospherically relevant initial $\mathrm{SO}_{2}$ concentrations, the value of the uptake coefficient fell rapidly from an initial maximum value. Given that the amount of dust present in these laboratory experiments was many orders of magnitude greater than the heaviest loadings observed in field studies and would therefore be modified more slowly, the uptake coefficient will also decrease with time in the atmosphere. However the uptake parameters derived from the numerical model can be used to account for this.

A simple box model has been used, incorporating the proposed mechanism. The model parameters were taken from Table 2, but were corrected for the dust loading, as described in Sect. 4.3. The surface loading was set to $150 \mu \mathrm{g} \mathrm{m}^{-3}$ (Aymoz et al., 2004) which is equivalent to $8 \times 10^{-5} \mathrm{~cm}^{2} \mathrm{~cm}^{-3}$ (assuming the same BET surface area as the dust used in these experiments). If an initial mixing ratio of $10 \mathrm{ppt} \mathrm{SO}_{2}$ is used the lifetime is $\sim 5$ days. At $25 \mathrm{ppt} \mathrm{SO}_{2}$ the reactive sites on the external surface $\left(1.9 \times 10^{8} \mathrm{~cm}^{-3}\right)$ of the dust particles are quickly exhausted and diffusion into the pores slows further processing. This leads to a lifetime of $>200$ days. In all cases the time taken is greater than the lifetime of $7 \mathrm{~h}$ calculated using the initial uptake coefficient measured in this work. In comparison, the lifetime of $\mathrm{SO}_{2}$ with respect to reaction with $\mathrm{OH}$ is $\sim 11$ days if $[\mathrm{OH}]=1 \times 10^{6}$ molecule $\mathrm{cm}^{-3}$. During the same period an initial mixing ratio of 250 ppt would have fallen by $\sim 15 \%$ and of 25 ppt by $\sim 41 \%$, because of processing on mineral dust, given the conditions used above. Hence, the removal of gas-phase $\mathrm{SO}_{2}$ by mineral dust is relatively more important at lower mixing ratios and higher dust loadings.

In the presence of ozone, $\mathrm{SO}_{2}$ chemisorbed onto mineral dust can be oxidised to sulphate. The sulphate content of mineral dust aerosols derived from oxidation of surface bound $\mathrm{SO}_{2}$ has been measured recently as $<1.7 \mu \mathrm{g} \mathrm{m}^{-3}$ (Aymoz et al., 2004). The source of the mineral dust particles was $\sim 3$ days from the measurement site. Running the box model for $72 \mathrm{~h}$, with an initial $\mathrm{SO}_{2}$ mixing ratio of $250 \mathrm{ppt}$ (Aymoz et al., 2004) gives a sulphate concentration of $0.1 \mu \mathrm{g} \mathrm{m}^{-3}$, consistent with the measured upper limit.

Acknowledgements. We would like to thank L. Gomes and J. Crowley for supplying the Cape Verde loess sample, A. Orlov and S. Saracevic for the BET measurements, Leica Micro Systems Lithography Ltd, Cambridge for donation of equipment and P. Griffiths and M. Fernandez for helpful discussions. J. W. Adams acknowledges the funding of the Natural Environment Research Council, UK. D. Rodriguez is grateful to Junta de Comunidades de Castilla-La Mancha for financial support.

Edited by: M. Ammann

\section{References}

Ammann, M., Pöschl, U., and Rudich, Y.: Effects of reversible adsorption and Langmuir-Hinshelwood surface reactions on gas uptake by atmospheric particles, Phys. Chem. Chem. Phys., 5, 351-356, 2003.

Andreae, M. O., Andreae, T. W., Meyerdierks, D., and Thiel, C.: Marine sulfur cycling and the atmospheric aerosol over the springtime North Atlantic, Chemosphere, 52, 1321-1343, 2003.

Aymoz, G., Jaffrezo, J.-L., Jacob, V., Colomb, A., and George, C.: Evolution of organic and inorganic components of aerosol during a Saharan dust episode observed in the French Alps, Atmos. Chem. Phys., 4, 2499-2512, 2004,

SRef-ID: 1680-7324/acp/2004-4-2499.

Börensen, C.: Kinetische und mechanistische Untersuchung der heterogenen Reaktionen von Stickoxiden an MineralstaubOberflächen, PhD thesis, University of Essen, Essen, Germany, 2000.

Brown, R. L.: Tubular flow reactors with first-order kinetics, J. Res. Nat. Bur. Standards, 83, 1-8, 1978.

Chameides, W. L. and Stelson, A. W.: Aqueous-phase chemical processes in deliquescent sea-salt aerosols - a mechanism that couples the atmospheric cycles of S and sea salt, J. Geophys. Res.-A, 97, 20 565-20 580, 1992.

Cox, R. A., Fernandez, M. A., Symington, A., Ullerstam, M., and Abbatt, J. P. D: A kinetic model for uptake of $\mathrm{HNO} 3$ and $\mathrm{HCl}$ on ice in a coated wall flow system, Phys. Chem. Chem. Phys., 7, 3434-3442, 2005

Curtis, A. R. and Sweetenham, W. P.: FACSIMILE, AERE Harwell, Publication R 12805, Computer Science and Systems Division, Harwell Laboratory, Oxfordshire, U.K., 1987.

Dentener, F. J., Carmichael, G. R., Zhang, Y., Lelieveld, J., and Crutzen, P. J.: Role of mineral aerosol as a reactive surface in the global troposphere, J. Geophys. Res.-A, 101, 22 869-22 889, 1996.

Dutkiewicz, V. A., Das, M., and Husain, L.: The relationship between regional $\mathrm{SO}_{2}$ emissions and downwind aerosol sulfate concentrations in the northeastern US, Atmos. Environ., 34, 1821-1832, 2000.

Formenti, P., Andreae, M. O., Lange, L., Roberts, G., Cafmeyer, J., Rajta, I., Maenhaut, W., Holben, B. N., Artaxo, P., and Lelieveld, J.: Saharan dust in Brazil and Suriname during the Large-Scale Biosphere-Atmosphere Experiment in Amazonia (LBA) - Cooperative LBA Regional Experiment (CLAIRE) in March 1998, J. Geophys. Res.-A, 106, 14 919-14 934, 2001.

Goodman, A. L., Li, P., Usher, C. R., and Grassian, V. H.: Heterogeneous uptake of sulfur dioxide on aluminum and magnesium oxide particles, J. Phys. Chem. A, 105, 6109-6120, 2001.

Hanisch, F. and Crowley, J. N.: Ozone decomposition on Saharan dust: an experimental investigation, Atmos. Chem. Phys., 3, 119-130, 2003,

SRef-ID: 1680-7324/acp/2003-3-119. 
Hanke, M., Umann, B., Uecker, J., Arnold, F., and Bunz, H.: Atmospheric measurements of gas-phase $\mathrm{HNO}_{3}$ and $\mathrm{SO}_{2}$ using chemical ionization mass spectrometry during the MINATROC field campaign 2000 on Monte Cimone, Atmos. Chem. Phys., 3, 417436, 2003,

SRef-ID: 1680-7324/acp/2003-3-417.

Hirschfelder, J. O., Curtiss, C. F., and Bird, R. B.: The kinetic theory of dilute gases, in: Molecular theory of gases and liquids, John Wiley and Sons, New York, 441-511, 1954.

Howard, C. J.: Kinetic measurements using flow tubes, J. Phys. Chem., 83, 3-9, 1979.

Judeikis, H. S., Stewart, T. B., and Wren, A. G.: Laboratory Studies of heterogeneous reactions of $\mathrm{SO}_{2}$, Atmos. Environ., 12, 16631641, 1978.

Keene, W. C., Sander, R., Pszenny, A. A. P., Vogt, R., Crutzen, P. J., and Galloway, J. N.: Aerosol pH in the marine boundary layer: A review and model evaluation, J. Aerosol. Sci., 29, 339-356, 1998.

Keyser, L. F., Moore, S. B., and Leu, M.-T.: Surface reaction and pore diffusion in flow-tube reactors, J. Phys. Chem., 95, 54965502, 1991.

Krischke, U., Staubes, R., Brauers, T., Gautrois, M., Burkert, J., Stobener, D., and Jaeschke, W.: Removal of $\mathrm{SO}_{2}$ from the marine boundary layer over the Atlantic Ocean: A case study on the kinetics of the heterogeneous S(IV) oxidation on marine aerosols, J. Geophys. Res.-A, 105, 14 413-14 422, 2000.

Maahs, H. G.: Kinetics and mechanism of the oxidation of S(IV) by ozone in aqueous-solution with particular reference to $\mathrm{SO}_{2}$ conversion in nonurban tropospheric clouds, J. Geophys. Res.A, 88, 721-732, 1983.

Mamane, Y. and Gottlieb, J.: Heterogeneous reactions of minerals with sulfur and nitrogen-oxides, J. Aerosol. Sci., 20, 303-311, 1989.

Penner, J. E., Andreae, M., Annegarn, H., et al.: Aerosols, their direct and indirect effects, in: Climate Change 2001: The Scientific Basis, Contribution of Working Group I to the Third Assessment Report of the Intergovernmental Panel on Climate Change, edited by: Houghton, J. T. et al., Cambridge Univ. Press, Cambridge, UK, and New York, NY, USA, 291-336, 2001.

Prospero, J. M.: Long-range transport of mineral dust in the global atmosphere: Impact of African dust on the environment of the southeastern United States, Proc. Natl. Acad. Sci. U.S.A., 96, 3396-3403, 1999.
Prospero, J. M., Ginoux, P., Torres, O., Nicholson, S. E., and Gill, T. E.: Environmental characterization of global sources of atmospheric soil dust identified with the Nimbus 7 Total Ozone Mapping Spectrometer (TOMS) absorbing aerosol product, Rev. Geophys., 40, art. no. 1002, 2002.

Song, C. H. and Carmichael, G. R.: The aging process of naturally emitted aerosol (sea-salt and mineral aerosol) during long range transport, Atmos. Environ., 33, 2203-2218, 1999.

Timonen, R. S., Chu, L. T., Leu, M.-T., and Keyser, L. F.: Heterogeneous reaction of $\mathrm{ClONO}_{2}(\mathrm{~g})+\mathrm{NaCl}(\mathrm{s}) \rightarrow \mathrm{Cl}_{2}(\mathrm{~g})+\mathrm{NaNO}_{3}$ (s), J. Phys. Chem., 98, 9509-9517, 1994.

Tang, Y. H., Carmichael, G. R., Kurata, G., Uno, I., Weber, R. J., Song, C. H., Guttikunda, S. K., Woo, J. H., Streets, D. G., Wei, C., Clarke, A. D., Huebert, B., and Anderson, T. L.: Impacts of dust on regional tropospheric chemistry during the ACE-Asia experiment: A model study with observations, J. Geophys. Res.A, 109, art. no. D19S21, 2004.

Ullerstam, M., Vogt, R., Langer, S., and Ljungstrom, E.: The kinetics and mechanism of $\mathrm{SO}_{2}$ oxidation by $\mathrm{O}_{3}$ on mineral dust, Phys. Chem. Chem. Phys., 4, 4694-4699, 2002.

Ullerstam, M., Johnson, M. S., Vogt, R., and Ljungstrom, E.: DRIFTS and Knudsen cell study of the heterogeneous reactivity of $\mathrm{SO}_{2}$ and $\mathrm{NO}_{2}$ on mineral dust, Atmos. Chem. Phys., 3, 2043-2051, 2003,

SRef-ID: 1680-7324/acp/2003-3-2043.

Underwood, G. M., Li, P., Usher, C. R., and Grassian, V. H.: Determining accurate kinetic parameters of potentially important heterogeneous atmospheric reactions on solid particle surfaces with a Knudsen cell reactor, J. Phys. Chem. A, 104, 819-829, 2000.

Usher, C. R., Al-Hosney, H., Carlos-Cuellar, S., and Grassian, V. H.: A laboratory study of the heterogeneous uptake and oxidation of sulfur dioxide on mineral dust particles, J. Geophys. Res.-A, 107, art. no. 4713, 2002.

Usher, C. R., Michel, A. E., and Grassian, V. H.: Reactions on mineral dust, Chem. Rev., 103, 4883-4939, 2003.

VanCuren, R. A. and Cahill, T. A.: Asian aerosols in North America: Frequency and concentration of fine dust, J. Geophys. Res.A, 107, art. no. 4804, 2002. 